\title{
Petromagnetic properties in the Naica mining district, Chihuahua, Mexico: Searching for source of mineralization
}

\author{
L. M. Alva-Valdivia, A. Goguitchaichvili, and J. Urrutia-Fucugauchi \\ Laboratorio de Paleomagnetismo y Geofisica Nuclear, Instituto de Geofisica, Universidad Nacional Autonoma de Mexico, \\ 04510 Coyoacan, Mexico D. F., Mexico
}

(Received November 5, 2001; Revised November 6, 2002; Accepted November 7, 2002)

\begin{abstract}
Ore mineral and host lithologies have been sampled at 14 sites (89 oriented samples) in the Naica District, northern Mexico. The following properties were measured to characterise samples: saturation magnetization, high-temperature magnetic susceptibility, remanence intensity, Koenigsberger ratio, Curie temperature and hysteresis parameters. Rock magnetic properties seem to be controlled by variations in pyrrhotite, (titano)magnetite, (titano)hematite and (titano)maghemite content, and hydrothermal alteration. Post-mineralization hydrothermal alteration seems to be the major event that affected the minerals and magnetic properties. Continuous susceptibility measurements with temperature in most cases yield Curie points close to that of almost pure magnetite. Hysteresis curves and associated IRM (isothermal remanent magnetization) acquisition plots, however, in some cases points to the higher coercivity minerals. Hematite or a mixture of hematite-titanomagnetite-titanomaghemite are probably present in the Naica samples although their contribution in remanent magnetization is minor. Judging from the ratios of hysteresis parameters, it seems that all samples fall into the pseudo-single domain (PSD) grain size region. The Koenigsberger ratio $(Q)$ was used as a measure of the relative contribution of remanent and induced magnetization into the magnetic anomalies. $Q$ ranges from 0.05 to 34 and, generally, it is higher than 1 , indicating the predominance of remanence over induced magnetism. The location and geometry of the magnetic source is shown as a single long subhorizontal body slightly inclined $\left(\sim 20^{\circ}\right)$ to the SE. This modelled body suggests an andine-type nature and emplacement of granitic magmas.
\end{abstract}

\section{Introduction}

The Naica mining district is located in the central-southern sector of Chihuahua state $\left(27^{\circ} 52^{\prime} 00^{\prime \prime}\right.$ North, and $105^{\circ} 26^{\prime} 15^{\prime \prime}$ West, Fig. 1). It is a chimney-manto, limestone-replacement, skarn-sulfide deposit that has produced much of the silver, lead, and zinc production of Mexico. Nevertheless, significant uncertainty remains concerning the conditions under which this deposit was formed, and what kind of fluids are required to deposit extensive cylinders and sheets of ore, skarn, and other gangue minerals that extend through massive limestone for thousands of meters beyond confirmed or inferred intrusive rocks. The mineralogy of these deposits, especially the skarn-bearing ores, suggests that they formed over a wide range of temperatures $\left(120-680^{\circ} \mathrm{C}\right.$, Erwood et al., 1979).

Naica mine is located at the northeastern side of a dome extending to the northwest (Fig. 1). The Naica deposit consists of at least 10 mantos and 40 chimneys that have produced over 21 million tons of ore since 1951. The host rock for the ore is thickly bedded Cretaceous limestones, folded into an elongated dome and cut by sparse pre-ore rhyolitic dikes thought to be related to the probable magmatic source of the Naica deposit (Erwood et al., 1979). This intrusive body is insinuated by a regional dome (Stone, 1959); a mag-

Copy right(C) The Society of Geomagnetism and Earth, Planetary and Space Sciences (SGEPSS); The Seismological Society of Japan; The Volcanological Society of Japan; The Geodetic Society of Japan; The Japanese Society for Planetary Sciences. netometric anomaly indicates that such an intrusion could be present at depth. This dome, very close to the Naica mine, hosts two caves (400 m depth) with the world's largest known selenite crystals, up to $16 \mathrm{~m}$ long.

This study is part of the long-term project to create a database of magnetic properties of rocks and minerals of Mexican and South American metallic deposits. This information is essential for the investigation of problems related to the magnetic history of rocks and magnetic anomalies.

The magnetic properties are used to constrain the range of feasible magnetometric models and provide information related to the composition, concentration, and microstructure of the magnetic mineral fraction. Thus, magnetic parameters are crucial for better comprehension of the relationship between geology, rock magnetism, and magnetic anomalies. This relation is complex because of the variability of the magnetic signature with respect to a rock unit, lithology, structure, and geologic history.

The aim of this work is to document the use of rock magnetic parameters to model the inferred intrusive body that produced the mineralization (e.g. Alva-Valdivia et al., 2000, 2001; Criss and Champion, 1984; Ketola et al., 1976). The magnetic model describes the shape, depth, and geometry of this source body, which are of interest to the exploration targets of new mineralized veins. 

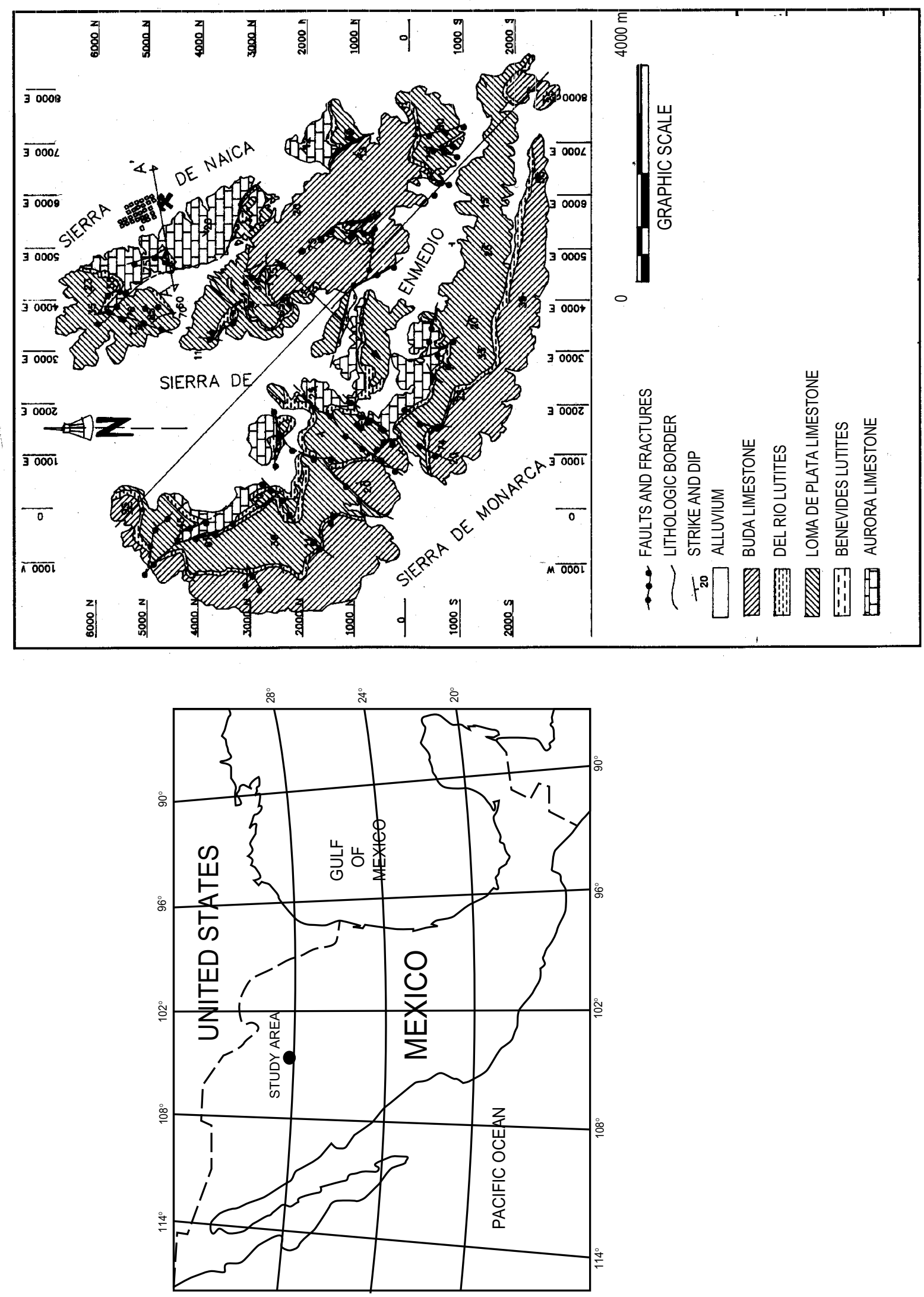


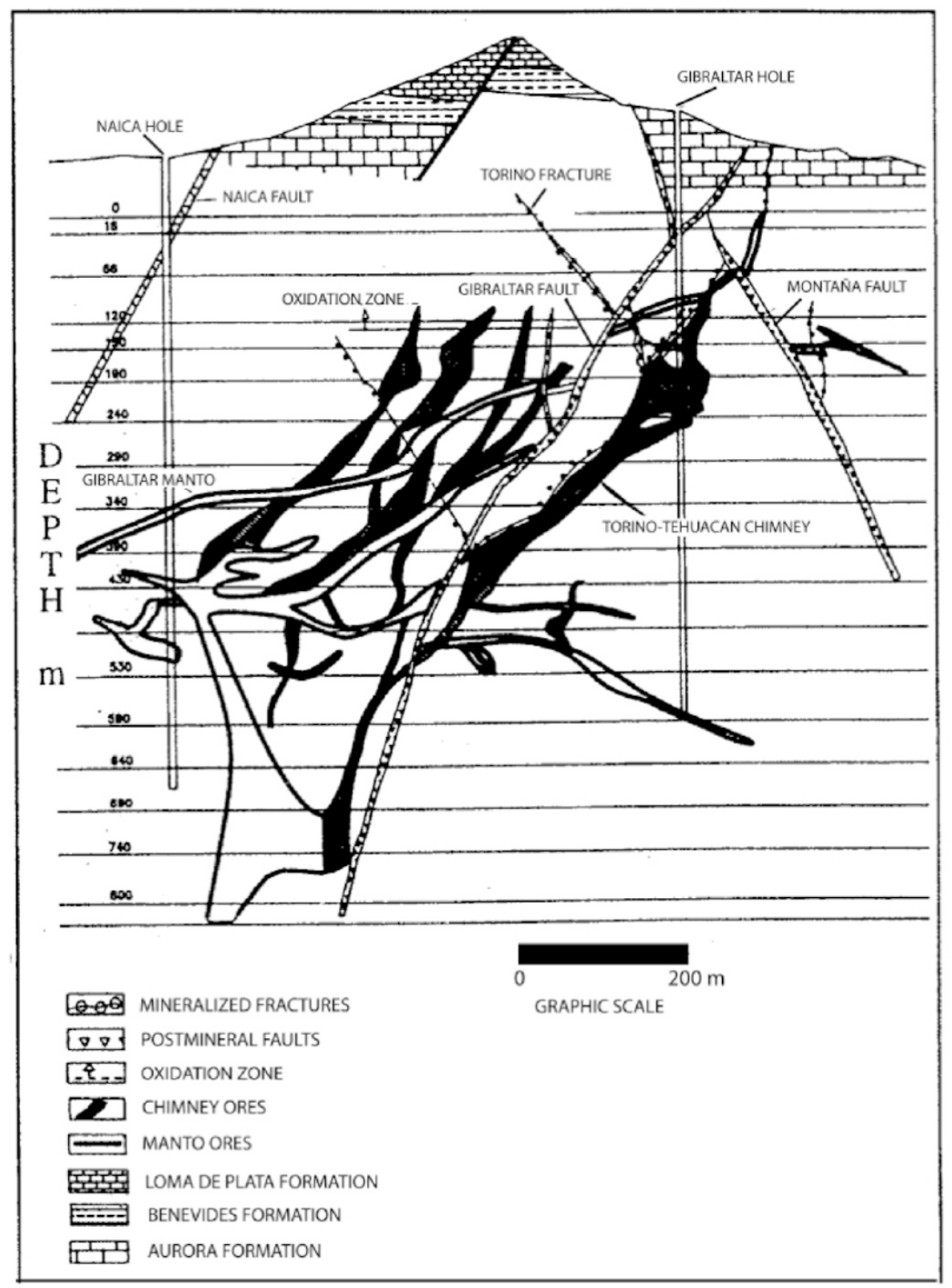

Fig. 2. Cross-section of the Naica Mine, showing major units and ore deposits.

\section{Geology and Ore Deposit Features}

The Naica mine has been intensively studied (see, e.g., Duarte, 1972; Erwood et al., 1979; Franco-Rubio, 1978; Haynes and Kesler, 1988; Stone, 1959). A summary of the main geologic and ore deposit features is given below.

Following Raisz's (1959) physiographic classification, Naica lies within the Basin and Range province, characterized by small isolated northwest-oriented ranges, located in the middle of extensive plains or bolsons. Locally, the mine lies in the northeast flank of an elongated domic structure NW-SE affected by small secondary folding, faulting, and erosion. This area represents a surface of $12 \mathrm{~km}$ long by $7 \mathrm{~km}$ wide formed by Sierra de Naica, Sierra de Enmedio, and Sierra de Monarca (Fig. 1).

The Naica mine is formed almost completely of pyrometasomatic and mesothermal replacement bodies of base-metal sulphides with minor amounts of silver and gold occurring in a thick sequence of locally marmorized Albian (Aurora, Benevides, and Loma de Plata Formations), late Albian to Cenomanian (Del Rio Formation), and early Cenomanian (Buda Formation) limestones (Fig. 2). The only igneous rocks known in the Sierra de Naica are thin, discontinuous felsite dikes and sills of very fine-grained quartz and feldspar that have themselves been altered and partly replaced during ore emplacement. The $\mathrm{K} / \mathrm{Ar}$ dates for these dikes range from $26 \mathrm{Ma}$ (Damon et al., 1981) to $30.2 \pm 0.8 \mathrm{Ma}$ (our determination: Geochron Laboratories Division of a whole rock andesitic dike core, using constants $\lambda_{\beta}=4.962 \times 10^{-10} /$ year, $\left(\lambda_{e}+\lambda_{e}^{\prime}\right)=0.581 \times 10^{-4} /$ year, $\left.{ }^{40} \mathrm{~K} / \mathrm{K}=1.193 \times 10^{-4} \mathrm{~g} / \mathrm{g}\right)$ placing them in the Oligocene.

Ore emplacement in the district was controlled by dikes and sills and steeply dipping NW and NE fractures. Fluid movement took place on faults belonging to both of these fractures sets before, during, and after the period of mineral- 


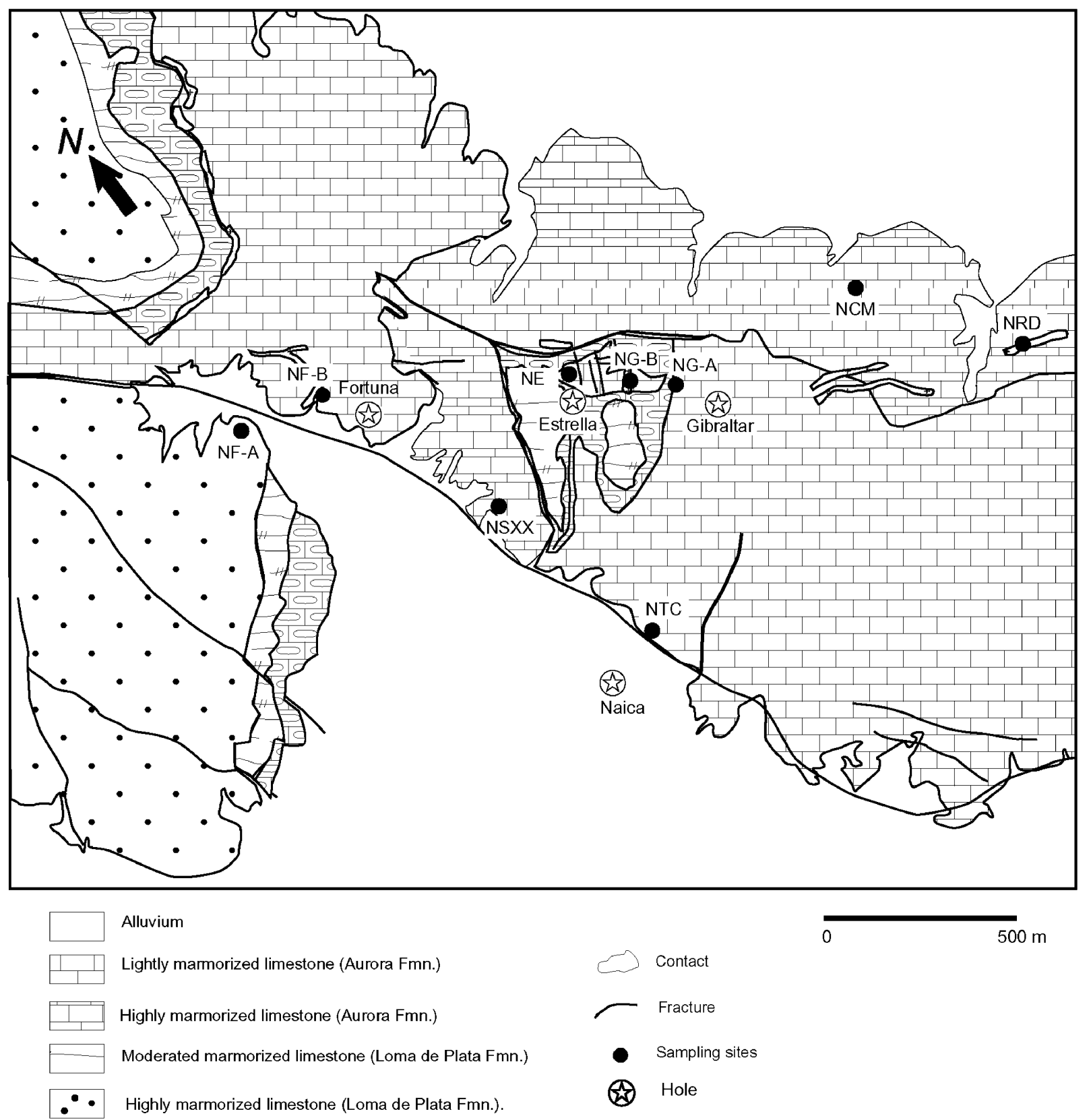

Calcareous lutite (Benevides Fmn.)

Fig. 3. Simplified geologic map of the Naica mining district showing the location of sampling sites.

ization. Two structural types of orebody are exposed: gently dipping silicate-sulphide sheets, or "mantos" and steeply plunging chimneys of sulphide ore with or without minor amounts of silicates, localized along steep NE or NW faults (Fig. 2 see section A-A' and Fig. 3).

The amount of iron carried by the fluid increased markedly with respect to lead and zinc during mineralization in the district. While the oxidation state of the fluid as a whole remained nearly constant with time, it had been changing, due solely to the drop in temperature, during crystallization within each successive orebody (Haynes and Kesler, 1988). The inferred changes in the mineralizing fluid with time are virtually identical to changes in the mantos produced by the progressive reaction of the fluid with limestone (Erwood, 1979; Haynes and Kesler, 1988).

Mineralogical and geochemical data (Haynes and Kesler, 1988) suggest that mineralization in Naica is of hydrothermal origin. The geothermal system resulted from the presence of an intrusive body, probably located at more than a depth of $1000 \mathrm{~m}$. Intrusion of this body and interaction with connate water of the sedimentary sequence created a hydrothermal system with high metal transport capacity brines. $\mathrm{Si}, \mathrm{Al}, \mathrm{Mn}, \mathrm{Fe}, \mathrm{Pb}, \mathrm{Zn}, \mathrm{Ag}, \mathrm{F}$, and S-rich brines rose following zones of weakness at the contact between felsic dikes 

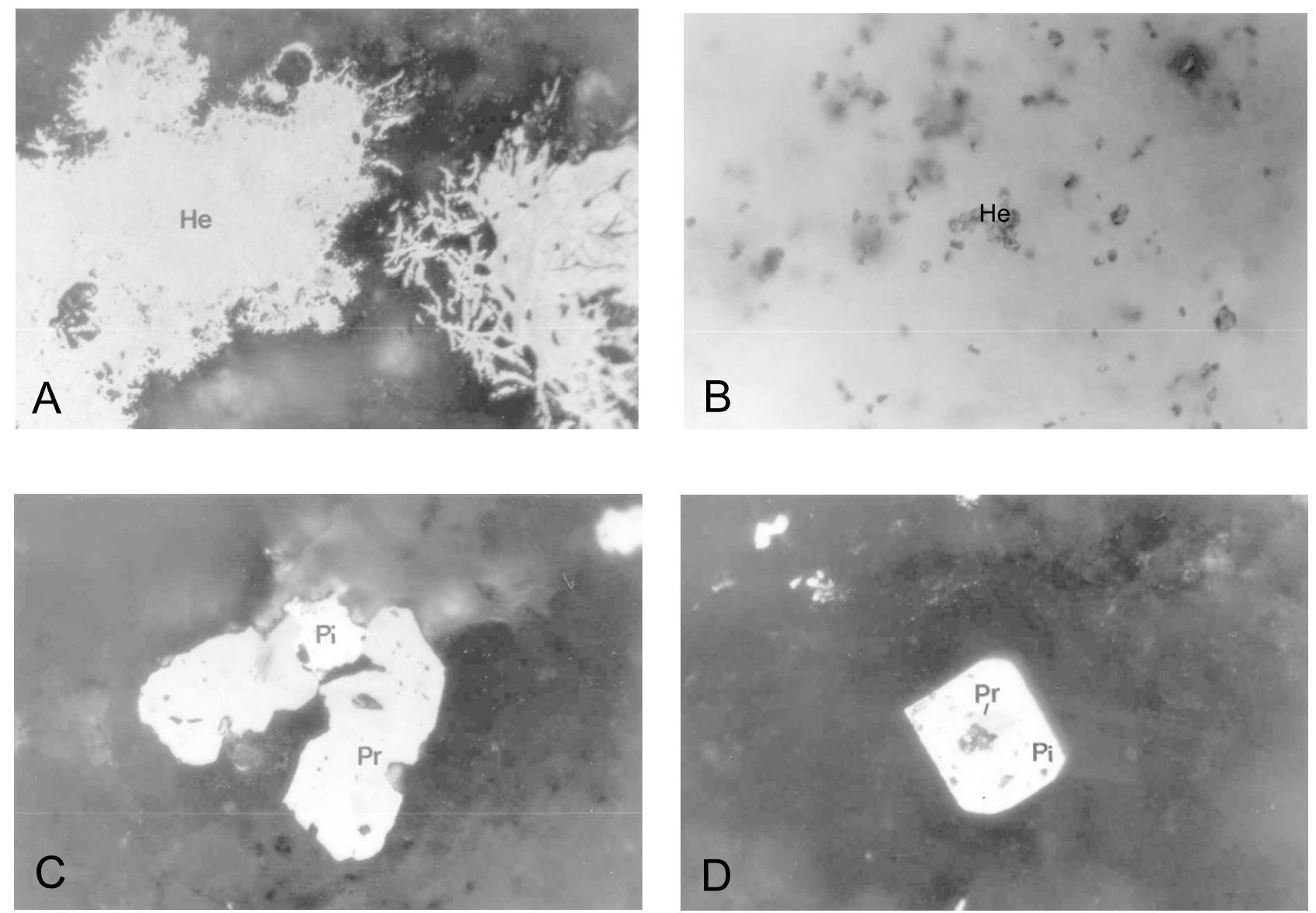

Fig. 4. Representative photomicrographs of the host rocks. Scale are as follows: Fig. 4(a), $1 \mathrm{~mm}=3.51 \mu \mathrm{m}$; Fig. 4(b), $1 \mathrm{~mm}=1.37 \mu \mathrm{m}$; Fig. 4 (c), $1 \mathrm{~mm}=0.54 \mu \mathrm{m}$; and Fig. $4(\mathrm{~d}), 1 \mathrm{~mm}=1.37 \mu \mathrm{m}$. Labels are as follows: $\mathrm{He}=$ hematite, $\mathrm{Pi}=$ pyrite, and $\mathrm{Pr}=$ pyrrhotite.

and limestones, where they interacted $(\mathrm{Ca}-\mathrm{Mg})$ to form new minerals.

Microscopic observations of magnetic oxides of the ore bodies (Querol and Trigos, 1996) suggest that all textures correspond to the replacement process of deposition. Only at the end of the hydrothermal process is there evidence of the dissolution of previously crystallized sulphides and the formation of vugs and cavities filled with late sulphides (mostly galena) and abundant fluorite, anhydrite, and dolomite (low temperature stage of gangue mineralogy). The main iron sulphides are pyrrhotite and pyrite, the later being more abundant, but there are also hematite, goethite, magnetite, and rutile $(<1 \%)$ at the end of the paragenetic sequence. Magnetite and rutile are exclusively present at the mantos. Pyrrhotite has been unstable under hydrothermal conditions after its deposition and is very often altered to pyrite-marcasite or pyrite-marcasite-hematite in a birds-eye texture. Precipitation of chalcopyrite and pyrrhotite is the first sign of massive sulphide mineralization. Finally, hematite and goethite replace intergranular borders and along fractures, representing the last hydrothermal pulse at Naica.

Because of geometrical relations and structural position, it is believed that the silicate mantos or bodies predate the chimney formation. The hydrothermal process occurred in the late Oligocene, probably corresponding with the last magmatic stages in the Sierra Madre Occidental.

We confirmed the Querol and Trigos (1996) interpreta- tions by observing selected samples under reflected light. Figure 4 shows some typical oxide minerals: (a) Sample $\mathrm{NFc}-3$ shows hematite in granular aggregates up to $150 \mu \mathrm{m}$ replaced on their borders by acicular goethite; (b) Sample Nga-2 shows granular sub-rounded hematite grains with less than $37 \mu \mathrm{m}$ size, homogeneously distributed; (c) and (d) sample NGb-5 shows that pyrite and pyrrhotite, pyrite is more abundant than pyrrhotite, is filling holes in the rock and is homogeneously distributed. Pyrite shows diverse irregular shapes, up to $15 \mu \mathrm{m}$, generally associated with pyrrhotite (c), sometimes it shows well-defined crystal shape with holes filled by pyrrhotite (d).

\section{Sampling and Experimental Methods}

Magnetic measurements were made on 14 sites (89 oriented drill-core samples) coming from characteristic surficial lithologies (10 sites) and cut subsurface exposures at several level depths (4 sites, see note under Table 1), which are distributed around the whole district (Fig. 3, Table 1). Commonly, the outcrops extend laterally over a few meters and in these cases we drilled typically $6-8$ cores per unit. At a few, small outcrops, only four cores were collected. The samples were distributed throughout each site both horizontally and vertically in order to minimize effects of block tilting and lightning. Cores were obtained with a gasoline-powered portable drill and then oriented in most cases with magnetic compass. 


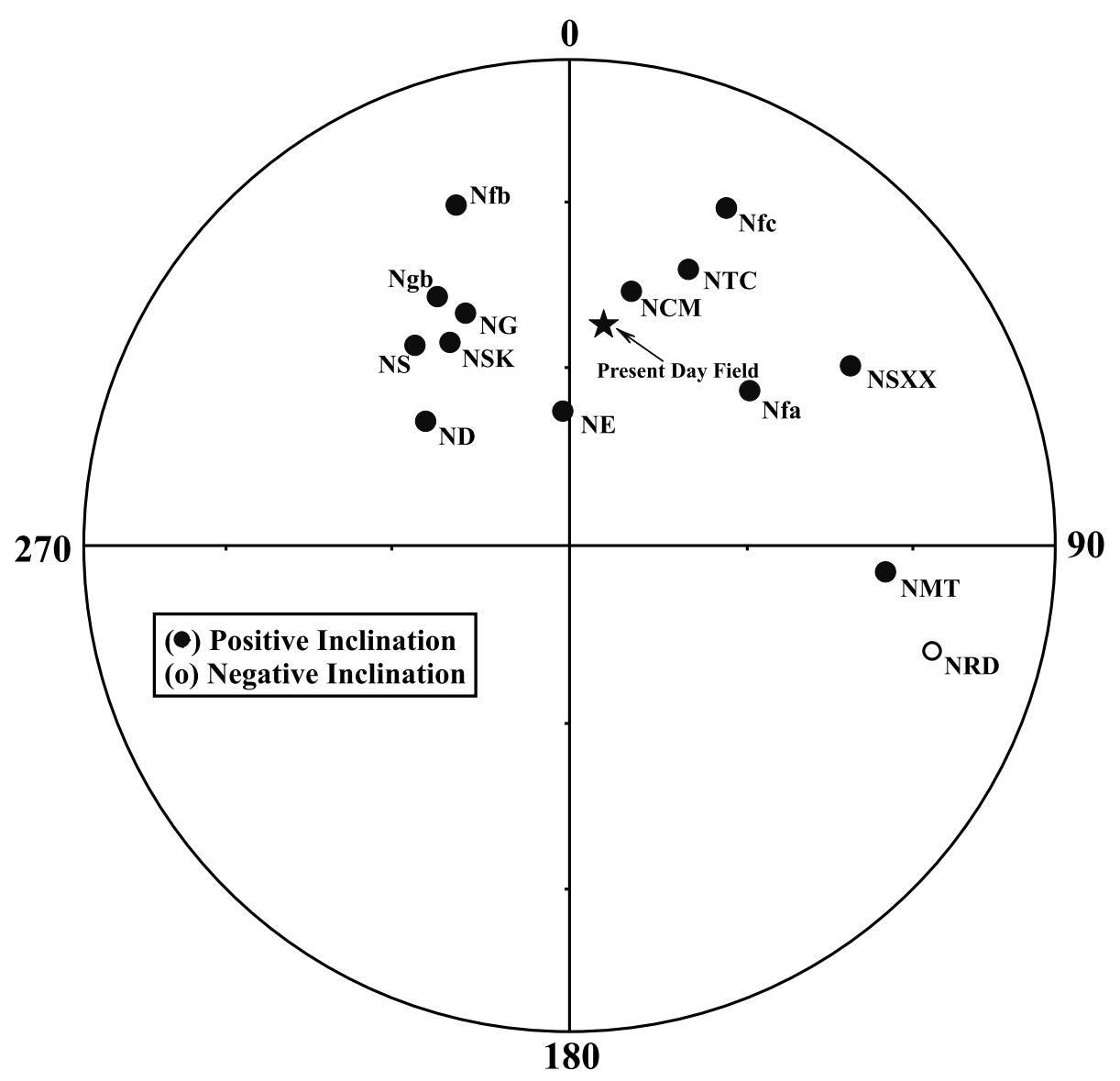

Fig. 5. The equal area projection (stratigraphic co-ordinates) of mean NRM directions for the various lithologies in Naica. Note that normal polarity is dominant.

Intensity and direction of natural remanent magnetization (NRM) and of laboratory isothermal remanent magnetization (IRM) were measured with a Molspin and a JR-5a spinner magnetometers. Separation of secondary magnetization components of low coercivity from the characteristic components was accomplished using a Schonstedt AF demagnetization apparatus, using 6-10 steps up to maximum fields of $100 \mathrm{mT}$, and thermal demagnetization carried out in 6-10 steps from room temperature up to $575^{\circ} \mathrm{C}$ in a TSD-1 noninductive electrical furnace.

Room temperature low-field magnetic susceptibility $k$ was determined with a Minisep (Molspin LtD) susceptibility meter. High-temperature susceptibilities were measured in air from room temperature up to $700^{\circ} \mathrm{C}$ (i.e., $k$ - $T$ curves) using a Highmoor instrument (home-made with $1^{\circ}$, resolution, and low-thermal drift) and a Bartington MS2 Magnetic Susceptibility System.

Magnetic hysteresis loops were measured with an alternating gradient force magnetometer (AGFM-MicroMag) in fields of up to $1.0 \mathrm{~T}$. Corresponding IRM acquisition curves and DC demagnetization were also acquired with this instrument using rock chips. Coercive force $H_{c}$, remanent coercive force $H_{c r}$, and saturation magnetization $M_{s}$, derived from the hysteresis loops, were used to try to infer the domain-type of magnetic minerals. All samples exhibited distinct behavior and showed a varying contribution of paramagnetic and diamagnetic minerals. This contribution was subtracted from the hysteresis loop to calculate magnetic parameters.

\section{Paleomagnetic Results}

Mean NRM directions for the 10 surface and four subsurface (from 290, 430, 480, and $530 \mathrm{~m}$ depth) sampling sites are shown in Fig. 5. Most rocks show normal polarity directions. Directions for unaltered ores are less scattered and lie closer to the present geomagnetic field ( $\operatorname{Dec}=9.1^{\circ}$, Inc $=51.5^{\circ}$ ) than directions for altered ore mixed with other minerals (see Table 1). The skarn sites show high withinsite angular dispersion and randomly distributed site-mean directions. Judging from the different directions shown by the different rock types, we are probably seeing the results of remagnetization due to hydrothermal alteration, with secondary components being acquired over an extended period from the Albian to the Oligocene. Characteristic paleodirections most probably have no geomagnetic significance because of hydrothermal alteration.

The vector plots also show a different behavior for each rock type (Fig. 6). The most common case is the isolation of one or two components, suggesting that the remagnetization processes affected the host rocks forming skarn and hornfels, the marmorized limestone, and the sulphide ore. An example with reasonably grouped direction that could result from contact metamorphism is showed in Fig. 6(A) (NSXX5-A) with a single component and no changes of direction. Calcareous lutites (Fig. 6(B), NG4-A) also yield stable one-component magnetic behavior during the demagnetization process. Felsitic dikes, which were sampled at the surface, altered the area of rock, (NRD) show three direc- 

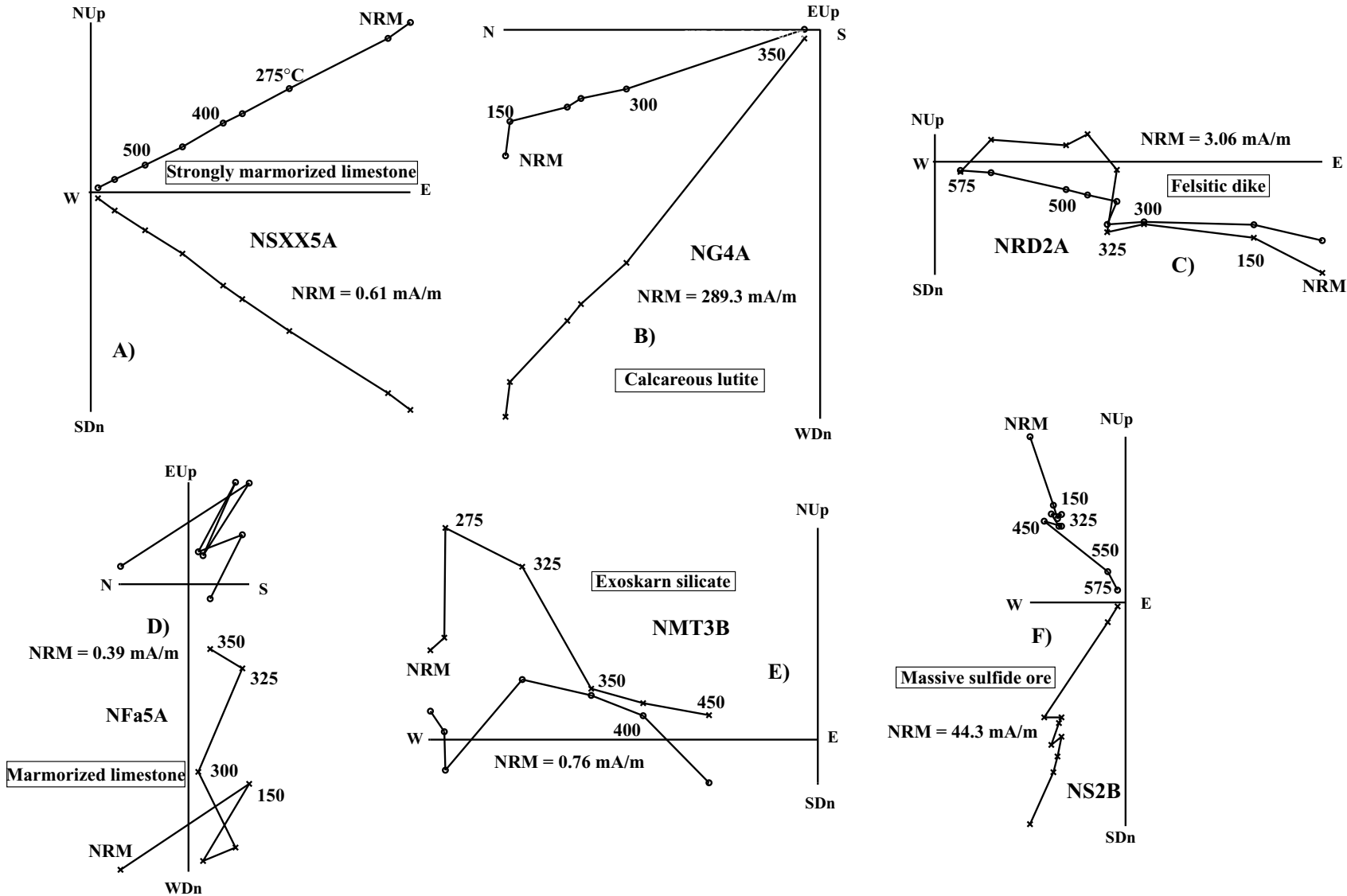

Fig. 6. Orthogonal vector plots of remanent magnetization for representative samples. The numbers refer to the temperatures in ${ }^{\circ} \mathrm{C}$. $\mathrm{o}-$ projections into the horizontal plane, $\mathrm{x}$-projections into the vertical plane.

tions during the demagnetization process (Fig. 6(C)). The Fisher statistic results are better for the ND [sampled inside the mine (fresh rock: this was the K/Ar dated sample)] site. Few samples of limestones show very erratic directions during the demagnetization process (Fig. 6(D)). Skarn silicates show at least two components with no-definition of characteristic components (Fig. 6(E)). Finally, the massive sulphide ore (Fig. 6(F)) is defined by two components.

The majority of the remanence was removed at temperatures of between 500 and $575^{\circ} \mathrm{C}$ (samples NSXX5A, NRD2A, NS2B) which points to almost pure magnetite as the remanence carrier. In some cases, however, unblocking temperatures range from 300 to $350^{\circ} \mathrm{C}$ (samples NG4A, NFa5A). This may correspond to the presence of pyrrhotite which was observed in polished sections (see Fig. 4) of Naica rocks. In case of massive sulphide ore (Fig. 6(F)), we observe a kind of standstill of remanence directions between 150 and $325^{\circ} \mathrm{C}$. Unblocking temperature spectra, however, is compatible to magnetite. As suggested by Bina and Daly (1994), ferrimagnetic pyrrhotite may transform irreversibly, usually to magnetite under some conditions, during thermal demagnetization of a rock.

\section{Rock-Magnetic Results}

\subsection{Magnetic hysteresis and IRM acquisition}

The representative hysteresis loops obtained for Naica samples are reported in Fig. 7. We note that hysteresis measurements were done on small chips and it is quite possible that bulk samples yield somewhat different magnetic properties.

Most curves are rather symmetrical in all cases (Figs. 7(a), (c), (d)). Near the origin, no potbellied and wasp-waisted behavior (Tauxe et al., 1996) was detected, which probably reflects the restricted dual ranges of the opaque mineral coercivities. However, the samples have very significant paramagnetic (Figs. 7(a), (b), (c)) or diamagnetic (Fig. 7(d), Table 1) contributions. The only exception is site NF (Fig. 7(b)), which probably reflects the presence of magnetic phases with different coercivities. Most probably, this behavior is due to presence of dominantly single domain and superparamagnetic titanohematite grains (Goguitchaichvili and Prévot, 2000).

Hysteresis parameters were formally calculated after correction for the paramagnetic/diamagnetic contribution (Table 1). $H_{c r} / H_{c}$ values range from 1.21 to 4.76 and $M_{r s} / M_{s}$ range from 0.03 to 0.43 which basically correspond to pseudo-single-domain (PSD) grain size region according to Day et al. (1977). Let us note that, if some superparamagnetic fraction exists in these samples, the measured coercive force would be somewhat lower and the saturation magnetization larger.

IRM acquisition curves (Fig. 7, right part) also yielded different behavior: In most of cases, the saturation is reached in low/moderate fields (150-200 mT, Figs. 7(a) and 6(d)), which may indicate that the ferromagnetic phase corresponds to some (titano)magnetites or (titano)maghemites. In other 

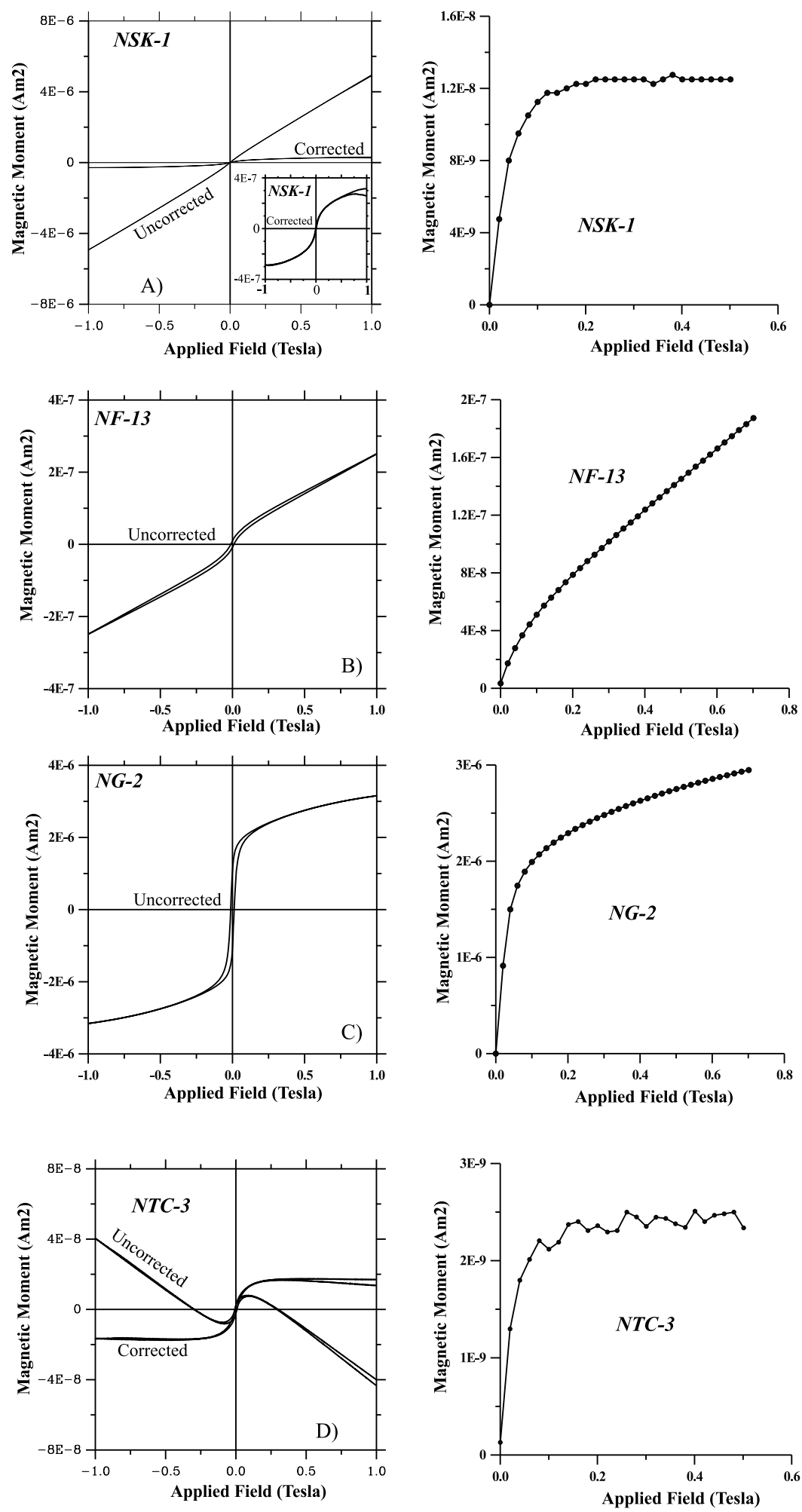

Fig. 7. Representative hysteresis loops for Naica samples and corresponding IRM acquisition curves (please also see the text).

cases, however, the saturation is not reached, even in the maximum available field (Figs. 7(b) and 7(c)). This behavior may belong to high coercivity mineral: (titano)hematite (Fig. 7(b)) or a mixture of (titano)hematite, titanohematite and titanomaghemite (Fig. 7(c)).

\subsection{NRM intensity, susceptibility, and Koenigsberger ratio}

Table 1 shows mean NRM intensity and susceptibility data of all surface and subsurface cores and Fig. 8 show the dependence of NRM vs susceptibility $(k)$. The variations in NRM intensity and susceptibility are due to two factors: the different volume contents of magnetic minerals, and the oc- 
currence of weakly magnetic or nonmagnetic phases generated at the expense of these minerals during oxidation or alteration processes. There are multiple or no trends in Fig. 8: only skarn, lutites, and massive sulfides show a reasonably well-defined increase of NRM with an increase of $k$. Among limestones, only the more strongly magnetized samples show the same trend. Samples with NRM intensity $<10^{-3} \mathrm{~A} / \mathrm{m}$, in contrast, show no significant increase with susceptibility. Finally, in dikes, intensity even tends to decrease slightly with an increase of $k$.

Average values of NRM intensity $M_{o}$, initial susceptibility, $k$, at room temperature, and Koenigsberger ratio $Q=M_{o} / k H$ (calculated for the present geomagnetic field $H=0.478$ Oe in the study area) are summarized in Table 1 . Koenigsberger ratios range from 0.06 to 34 , independently of susceptibility. This magnetic heterogeneity may result not only from high-temperature oxidation of primary titanomagnetites but mainly from hydrothermal alter-

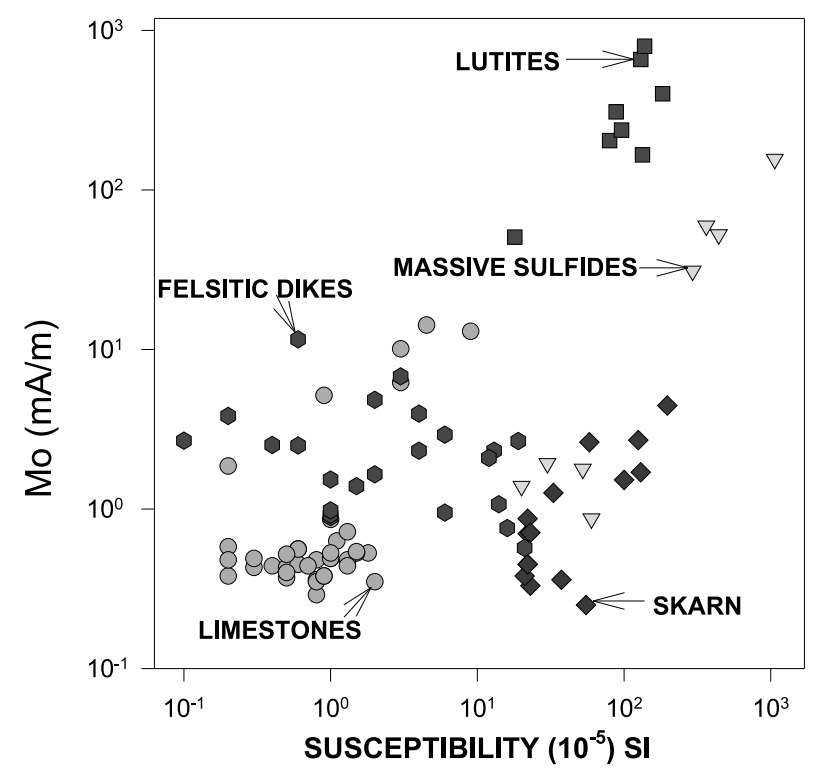

Fig. 8. NRM intensity against magnetic susceptibility for the Naica samples. ation, which transforms (titano)magnetite into magnetite, (titano)maghemite, (titano)hematite, rutile and sphene (Ueno and Tonouchi, 1987; Smith and Banerjee, 1986).

\subsection{Continuous susceptibility measurements}

Low-field susceptibility measurements ( $k-T$ curves) under air were carried out using a Highmoore susceptibility bridge equipped with a furnace. One sample from each site was heated up to about $600^{\circ} \mathrm{C}$ at a heating rate of $20^{\circ} \mathrm{C} / \mathrm{min}$ and then cooled at the same rate. The Curie temperature was determined by the Prévot et al.'s (1983) method. In most cases, $k-T$ curves could not be obtained due to weak initial magnetic susceptibilities. The samples (Figs. 9(a) and (b)) show an increase in susceptibility just below the Curie temperature (the Hopkinson peak), before dropping to relatively small values. This behavior probably corresponds to small PSD magnetic grains (Dunlop and Özdemir, 1997). The Curie point is $580 \pm 5^{\circ} \mathrm{C}$, which indicates nearly pure magnetite as a magnetic carrier. Rather irreversible behaviour was obtained from sample NSK2A (Fig. 9(c), endoskarn), that may be speculatively interpreted as evidence for some (titano)maghemites (Dunlop and Özdemir, 1997). Alternatively, the almost monotonic decrease of susceptibility from room temperature to about $380^{\circ} \mathrm{C}$ may indicate superparamagnetic fraction. As revealed by hysteresis measurements, hematite may exist in the Naica samples but the sensitivity of the Highmoore bridge is too low to detect it.

\section{Modeling of the Magnetometric Anomaly}

The anomaly in the area corresponds to a large normally polarized dipole, oriented almost north-south, that is possibly located over a major intrusive body (Fig. 10). For modeling the anomaly, we selected the profile $\mathrm{A}-\mathrm{A}^{\prime}$ that joins the lowest and highest peaks of the anomaly. The dipolar anomaly is characterized by a marked low and has peak-topeak amplitude of about $350 \mathrm{nT}$. The method used to calculate the magnetic model is based on the methods of Talwani et al. (1959) and Talwani and Heirtzler (1964) for twodimensional polygonal bodies (Talwani, 1965), and make use of the algorithms described in Won and Bevis (1987). The software used is GM-SYS by Northwest Geophysical
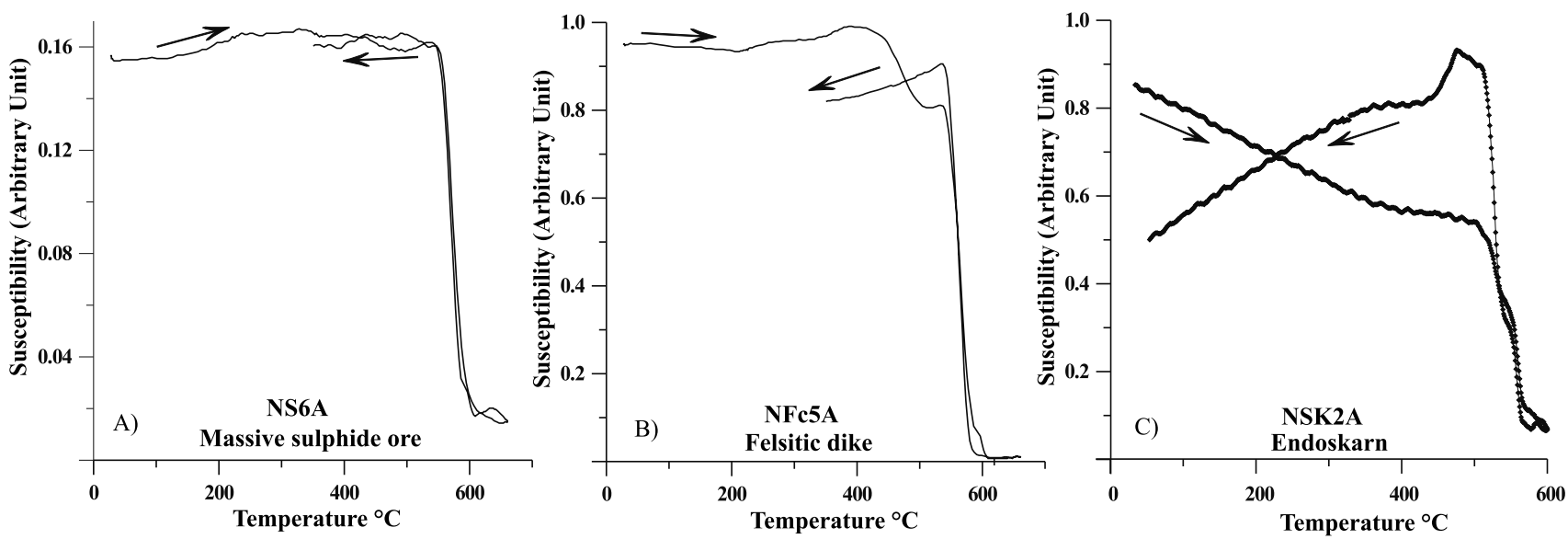

Fig. 9. $k$ - $T$ curves showing Curie temperatures close to $580^{\circ} \mathrm{C}$. These suggest that the main carrier of magnetization is almost pure magnetite. The arrows indicates the cooling and heating process 


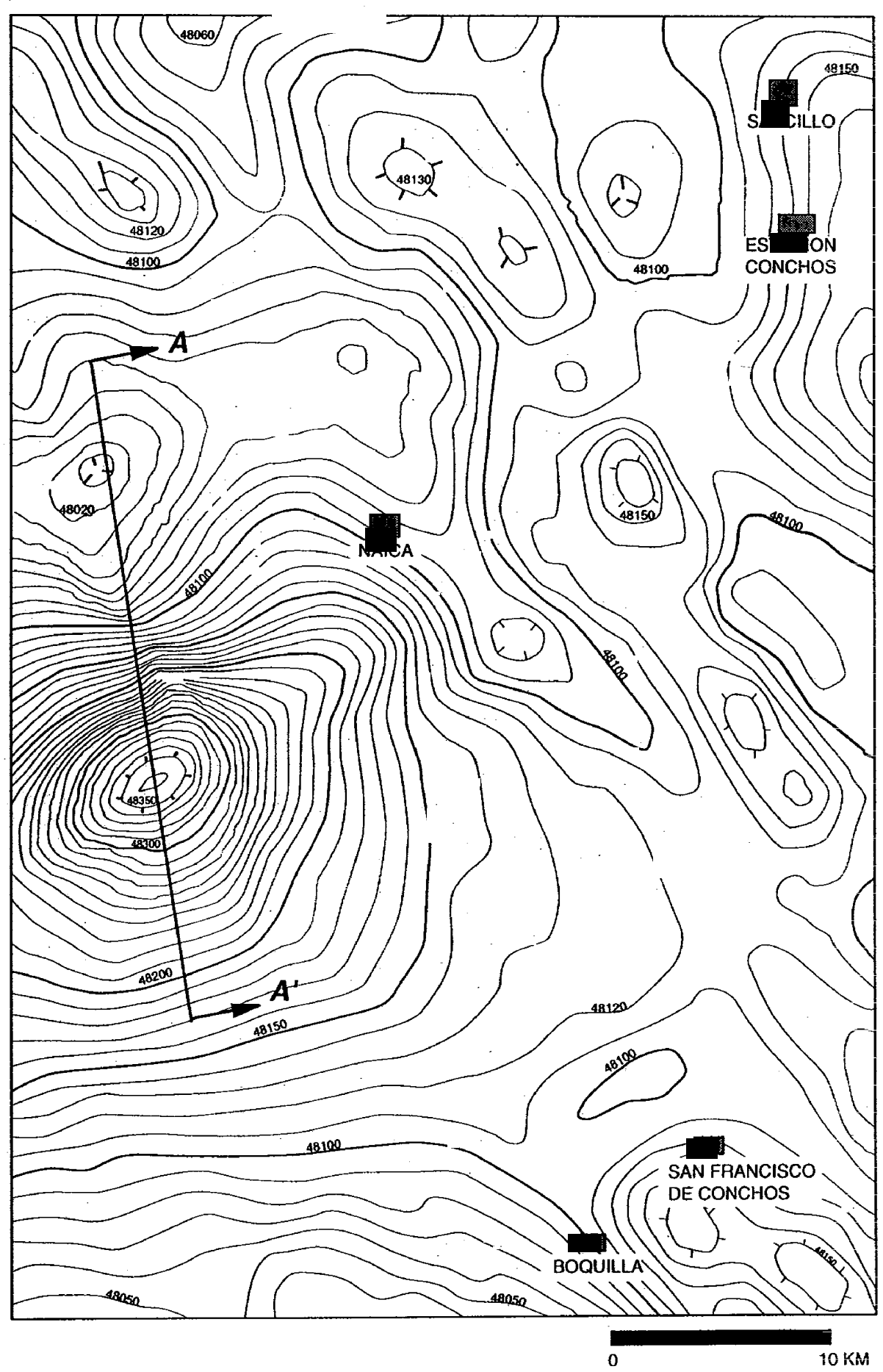

Fig. 10. Aeromagnetic anomaly map. Note the presence of a large dipolar anomaly located over the assumed intrusive body source of mineralization. Location of the modeled profile is shown. Values are given in nanoteslas.

Associate's geophysical staff.

We used the measured magnetic properties of the collected samples to constrain the modeling. This process was performed using several polygonal models with the magnetic properties of the ND site that correspond to a felsitic dike sampled at a depth of $530 \mathrm{~m}$. The main reason for doing this is that we assumed that the magnetic properties of the intrusive source of mineralization are of the same order as those of this dike. Hence, the best fit corresponds to an elon- gated body located beneath the maximum slope of the profile (Fig. 11). The model which produced an acceptable fit required susceptibilities on the order of $0.05 \times 10^{-3} \mathrm{SI}$, remanent intensity of $0.005 \mathrm{~A} / \mathrm{m}$, and direction of remanence of $\operatorname{Dec}=311^{\circ}$, Inc $=58^{\circ}$. The susceptibility value is the average of the three sites of sampled dikes (NFc, ND, and NRD). Consequently, the anomaly is generated by a major contribution of remanent magnetization (see the $Q$ ratio values). The ambiguity of this process was constrained, given as a conse- 

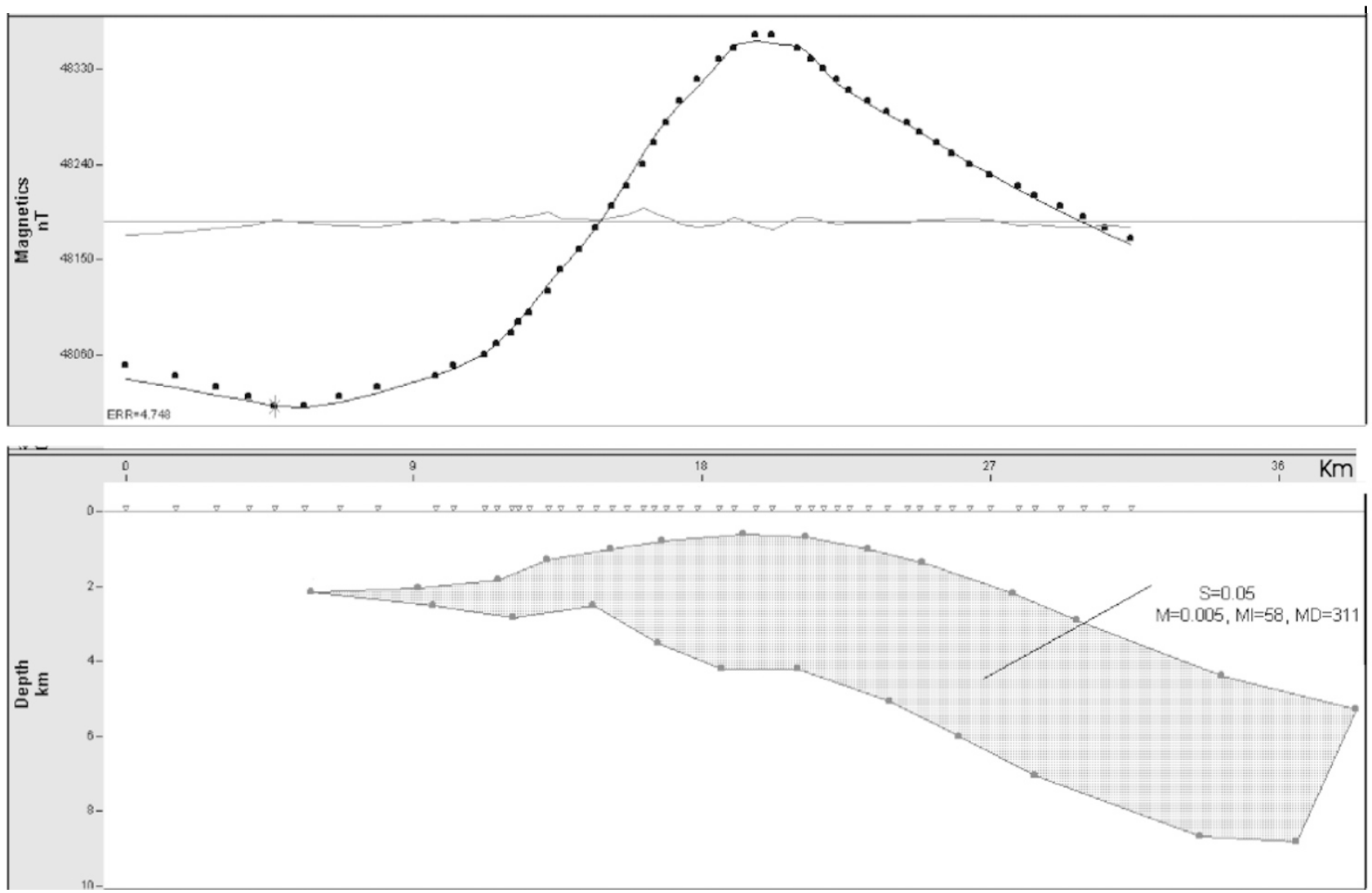

Fig. 11. Magnetic profile and quantitative model. Local geomagnetic field parameters are: declination $\mathrm{D}=9.8^{\circ}$, inclination $\mathrm{I}=56^{\circ}$, and total magnetic intensity $\mathrm{F}=47800 \mathrm{nT}$. We used profile strike $=90^{\circ}$ and one bidimensional body that extends infinitely perpendicular to this profile. Magnetic data for the body are: $\mathrm{NRM}$ declination $=311^{\circ}, \mathrm{NRM}$ inclination $=58^{\circ}$, remanent intensity $=0.005 \mathrm{~A} / \mathrm{m}$; and magnetic susceptibility $=0.05 \times 10^{-3}$ SI

quence a relatively small uncertainty in size, depth, and geometry of the proposed body. The fitted curve shows a slight deviation from that observed (see central line in Fig. 11), which is normal considering that there are many small contributor bodies. So, we consider that our approach is representative of the main source mineralized intrusive body that produced the magnetic anomaly.

\section{Discussion and Main Results}

The original titanomagnetites have been affected by highand low-temperature oxidation, contact metamorphism, and hydrothermal alteration; each of which leaves its imprint on petromagnetic properties. These properties suggest that host rocks and ores contain relatively large size (most probably of PSD structure) magnetic particles, justifying the low to medium values of magnetic susceptibility. This also implies medium intensity in the induced magnetization. The highest NRM values (site NG, Table 1) may suggest the presence of 'small PSD', or even SD particles, responsible for the major part of magnetization.

Susceptibility depends on many physical factors, among them the number, size, shape, and composition of magnetic grains and lattice imperfections and strain (e.g., Stacey and Banerjee, 1974). The contribution of diamagnetic and paramagnetic fraction should be necessarily considered in total susceptibility. Processes such as low-temperature oxidation, hydrothermal alteration, and metamorphism affect the sus- ceptibility because they change the quantity of magnetic material, its grain size and texture, and possibly the composition and degree of internal stress. Low-temperature oxidation, which frequently accompanies hydrothermal alteration, progressively transforms titanomagnetite to titanomaghemite and ultimately to sphene, rutile and hematite (Petersen et al., 1979). The general effect of these alteration processes is to reduce the size and quantity of magnetic grains by forming weakly magnetic or nonmagnetic minerals. Thus, alteration at low to moderate temperatures should cause susceptibility to decrease.

The range of $Q$ values (Table 1), from 0.06 to 34 may correspond to a variety of rocks (sedimentary, igneous, or metamorphic rocks according to Hunt et al. (1995)). There is a slight tendency for Koenigsberger ratios to decrease with increasing magnetic susceptibility. The scatter in the $Q$ value for the low-susceptibility rocks greatly exceeds the change in average $Q$ over three orders of magnitude of $k$ values. In the mono-mineralogical case, a variation of the volume content of magnetic minerals implies that $Q$ would remain constant. We may conclude that NRM intensity and susceptibility variations are primarily related to factors other than the content of magnetic minerals. Values of remanent intensity less than unity has a wide range for $Q$ coefficient values, showing a mixed predominance of induced and remanent magnetizations. The Koenigsberger ratio is used in the present work as a measure of the relative contribution of remanent and in- 
duced magnetization into the magnetic anomalies.

Paleomagnetic directions and polarities for host rocks and ore bodies do not provide firm constraints on stratigraphic relationships. Sulphide ores were likely formed around the time of intrusion in the lower to middle Tertiary.

The rock magnetic properties of sulphide ores and host rocks from the Naica deposit are controlled by original variations in pyrrhotite, (titano)magnetite, (titano)hematite, and possibly (titano)maghemite content, grain size and hydrothermal alteration. This later results in general decreases in the quantity and size of magnetite grains because of fracturing and replacement by nonmagnetic minerals. Our specific conclusions are as follows: (1) the sulphide ores are formed by hydrothermal fluids from an Oligocene intrusion (dated dike); (2) the main event that affected the minerals and magnetic properties was post-mineralization hydrothermal alteration, as evidenced by rock magnetic experiments; (3) the Curie temperatures determined from the $k-T$ curves are $580 \pm 5^{\circ} \mathrm{C}$, characteristic of pure magnetite; (4) the calculation of hysteresis parameters shows that most samples contain PSD particles; (5) both NRM and laboratory remanences are most probably carried by magnetite, pyrrhotite, and hematite; (6) NRM intensity and susceptibility range over three orders of magnitude and are, in some cases, proportional to each other; (7) for most of the samples, the Koenigsberger ratio between NRM and induced magnetization falls into a rather narrow range, with the exception of felsitic dikes with values differing by two orders of magnitude (range from 0.1 to 34 ); (8) paleomagnetic mean directions and polarities do not constraint the time of mineralization, although they may be of Middle Tertiary age as indicated by our K/Ar date; (9) Fig. 11 summarizes the quantitative interpretation of the observed magnetic anomaly. We used the intensity and direction of the NRM, and the induced intensity, for the calculated anomaly. The remanence component is larger than the induced component, corresponding to $Q$ coefficients larger than unity (site ND and NRD). The location and geometry of the magnetic source is shown as a long subhorizontal body slightly inclined $\left(\sim 20^{\circ}\right)$ to the southeast. This type of modeled body suggests an andine-type nature and emplacement of granitic magmas.

Acknowledgments. We are grateful for the kind cooperation of the Geological-Geophysical Division of the Naica district (Servicios Industriales Peñoles). This research was funded by CONACyT projects 32756-T, J32727-T and DGAPA projects IN-100100 and IN-102897.

\section{References}

Alva-Valdivia, L. M., J. Urrutia-Fucugauchi, A. Goguichaichvili, and D Dunlop, Magnetic mineralogy and properties of the Peña Colorada iron ore deposit, Guerrero Terrane: implications for magnetometric modeling, J. South Am. Earth Sciences, 13(5), 415-428, 2000.

Alva-Valdivia, L. M., J. Urrutia-Fucugauchi, A. Goguitchaichvili, and W. Vivallo, Rock-magnetism and ore microscopy of magnetite-apatite ore deposit from Cerro de Mercado, Mexico, Earth Planets Space, 53, 181192, 2001.

Bina, M. and L. Daly, Mineralogical change and self-reversed magnetization in pyrrhotite resulting from partial oxidation; geophysical implications, Phys. Earth Planet. Inter., 85, 83-99, 1994.

Criss, R. E. and D. E. Champion, Magnetic properties of granitic rocks from the southern half of the Idaho batholith: Influences of hydrothermal alteration and implications for aeromagnetic interpretation, J. Geophys. Res., 89(B8), 7061-7076, 1984.

Damon, P., M. Shafiqullah, and K. F. Clark, Age trends of igneous activity in relations to metallogenesis in the southern cordillera, in Relations of Tectonics to Ore Deposits in the Southern Cordillera, edited by E. R. Dickinson and W. D. Payne, Arizona Geol. Soc. 14, 137-154, 1981.

Day, R., M. Fuller, and V. A. Schmidt, Hysteresis properties of titanomagnetites: grain size and compositional dependence, Phys. Earth Planet. Inter., 13, 260-267, 1977.

Duarte, E. A., Geología de yacimientos minerales en el distrito de Naica, Estado de Chihuahua, AM. Inst. Min. Metal. Petrol. Eng., 43-59, 1972.

Dunlop, D. and Ö. Özdemir, Rock-Magnetism, Fundamentals and Frontiers, Cambridge Univ. Press, 573 pp., 1997.

Erwood, R. J., S. E. Kesler, and P. L. Cloke, Compositionally distinct, saline hydrothermal solutions, Naica Mine, Chihuahua, Mexico, Econ. Geol., 74, 95-108, 1979.

Franco-Rubio, M., Estratigrafia del Albiano-Cenomaniano en la region de Naica, Chihuahua, Rev. Inst. Geol., 2, 132-149, 1978.

Goguitchaichvili, A. and M. Prévot, Magnetism of oriented single crystals of hemo-ilmenite showing self-reversal of thermoremanent magnetization, J. Geophys. Res., 105, 2761-2781, 2000.

Haynes, F. M. and S. E. Kesler, Compositions and sources of mineralizing fluids for chimney and manto limestone-replacement ores in Mexico, Econ. Geol., 83, 1985-1992, 1988.

Hunt, C. P., B. M. Moskowitz, and S. K. Banerjee, Magnetic properties of rocks and minerals, in Rock Physics and Phase Relations: A Handbook of Physical Constants, edited by T. J. Ahrens, AGU Reference Shelf 3, 1995.

Ketola, M., M. Limatainen, and T. Ahokas, Application of petrophysics to sulphide ore prospecting in Finland, Pure Appl. Geophys., 114, 215-234, 1976.

Petersen, N., P. Eisenach, and U. Bleil, Low temperature alteration of magnetic minerals in ocean floor basalts, Deep drilling results in the Atlantic Ocean: Ocean Crust, American, 1979.

Prévot, M., R. S. Mainkinen, S. Grommé, and A. Lecaille, High paleointensity of the geomagnetic field from thermomagnetic studies on rift valley pillow basalts from the middle Atlantic ridge, J. Geophys. Res., 88, 23162326, 1983.

Querol, F. and G. Trigos, Ore mineralogy of the Naica Mine, Saucillo county, state of Chihuahua, in VI Excursion Geologica al Cenozoico de Chihuahua, Conferencia Internacional de Mineria Chihuahua-Batopilas del 6 al 9 de Octubre de 1996, 1996.

Raisz, E., Land forms of Mexico. Cambridge Mass, Map with text, scale 1:3,000,000, 1959.

Smith, G. M. and S. K. Banerjee, Magnetic structure of the upper kilometers of the marine crust at Deep Sea Drilling Project hole 504B, Eastern Pacific Ocean, J. Geophys. Res., 91, 10337-10354, 1986.

Stacey, F. D. and S. K. Banerjee, Physical properties of rock magnetism. Developments of Solid Earth Geophysics, 5, Elsevier, N. Y., 1974.

Stone, J. G., Ore genesis in the Naica district, Chihuahua, Mexico, Econ. Geol., 54, 1002-1034, 1959.

Talwani, M., Computation with the help of a digital computer of magnetic anomalies caused by bodies of arbitrary shape, Geophys., 20, 797-817, 1965.

Talwani, M. and J. R. Heirtzler, Computation of magnetic anomalies caused by two-dimensional bodies of arbitrary shape, in Computers in the Mineral Industries, Part 1, edited by G. A. Parks, Stanford Univ. Publ., Geological Sciences, 9, pp. 464-480, 1964.

Talwani, M., J. L. Worzel, and M. Landisman, Rapid gravity computations for two-dimensional bodies with application to the Mendocino submarine fracture zone, J. Geophys. Res., 64, 49-59, 1959.

Tauxe, L., T. A. T. Mullender, and T. Pick, Pot-bellies, wasp-waists and superparamagnetism in magnetic hysteresis, J. Geophys. Res., 95, 1233712350, 1996.

Ueno, H. and S. Tonouchi, Paleomagnetic evidence for the timing of formation of the Chichibu pyrometasomatic deposits, Japan. Econ. Geol., 82, 1723-1731, 1987.

Won, I. J. and M. Bevis, Computing the gravitational and magnetic anomalies due to a polygon: algorithms and Fortran subroutines, Geophys., 52, 232-238, 1987.

L. M. Alva-Valdivia (e-mail: lalva@tonatiuh.igeofcu.unam.mx), A. Goguitchaichvili, and J. Urrutia-Fucugauchi 